\title{
FORMAÇÃO PARA A INDÚSTRIA POR MEIO DA EDUCAÇÃO BÁSICA: ESTUDO DO PROJETO PEDAGÓGICO DO COLÉGIO SESI-PR
}

\author{
PREPARING STUDENTS TO WORK IN INDUSTRIES IN BASIC \\ EDUCATION: AN ANALYSIS OF THE POLITICAL PEDAGOGICAL \\ PROJECT OF THE SESI-PR SCHOOL
}

\author{
Andrieli Almeida Camargo* \\ Alessandro de Melo**
}

\begin{abstract}
RESUMO
Este trabalho visa analisar os fundamentos do Projeto Político-Pedagógico do Colégio Sesi-PR, com vistas à compreensão de sua vinculação com as demandas da indústria para a educação básica na contemporaneidade. Objetiva-se categorizar o PPP do Colégio Sesi-PR e relacioná-lo aos elementos fundantes do projeto de educação básica do empresariado brasileiro, tendo como referencial o marxismo e, portanto, visando à compreensão das relações entre trabalho e educação no contexto das políticas educacionais para o ensino médio. $\mathrm{O}$ artigo tem por base a análise bibliográfica de autores que estudam o mundo do trabalho e a educação do trabalhador e analisa o discurso do empresariado industrial na formação de jovens para atuar no mercado de trabalho, com uma proposta neotecnicista, adaptandoos às demandas da indústria.
\end{abstract}

Palavras-chave: Empresariado e educação. Projeto Político-Pedagógico. Trabalho e educação.

\begin{abstract}
This study aims to examine the fundamentals of the Political Pedagogical Project (PPP) of the SESI-PR School in order to understand its link with industry demands for basic education nowadays. The objective is to categorize the PPP of the SESI-PR School and relate it to the founding elements of the basic education project of Brazilian business. The study takes Marxism as a reference and aims to understand the relationships between work and education in the context of educational policies for high school. The study is based on the literature review of authors who study the world of work and worker education. The study analyzes the discourse of the industrial business in the training of young people to act in the labor market, with a neo technicist proposal, adapting them to the demands of industry.
\end{abstract}

Keywords: Entrepreneurship and education. Political Pedagogical Project. Work and education.

\footnotetext{
* Licenciada em Pedagogia pela Universidade Estadual do Centro-Oeste, campus Santa Cruz, Guarapuava-PR. E-mail: andrieli.almeida@hotmail.com

** Doutor em Educação pela Universidade Federal do Paraná. Professor do Departamento de Pedagogia da Universidade Estadual do Centro-Oeste, campus Santa Cruz, Guarapuava-PR. Professor do Programa de Pós-Graduação em Educação da Universidade Federal do Paraná. E-mail: alessandrodemelo2006@ hotmail.com
} 


\section{Introdução}

No capitalismo encontramos a simplificação e a desqualificação do trabalhador por meio da divisão do trabalho, do uso de máquinas e da incorporação das técnicas de racionalização gerenciais da administração desenvolvidas ao longo da história. Nesse contexto, cabe à educação o papel de coagir e adaptar os indivíduos à sociedade, marcada pela dominação de classes.

Este artigo tem por objetivo central analisar como ocorre a formação dos trabalhadores que irão atuar na indústria por meio da educação básica. Para isso, realizou-se uma leitura crítica do Projeto Político-Pedagógico (PPP) do Colégio Sesi-PR, buscando categorizar o PPP e relacionando-o aos elementos fundantes do projeto de educação básica do empresariado industrial brasileiro.

A metodologia adotada para a realização da pesquisa baseia-se no referencial marxista, tendo como ponto de partida a análise do Projeto Político-Pedagógico do Colégio Sesi-PR, a proposta da Confederação Nacional da Indústria e bibliografias de autores que estudam criticamente o mundo do trabalho e a educação do trabalhador. A intenção é que, a partir deste estudo, compreendam-se os mecanismos conjunturais que relacionam as demandas do trabalho capitalista e os projetos educacionais propostos pelos empresários, fazendo com isso o movimento dialético do particular (concreto) para o geral (abstrato) e, novamente, para o particular (concreto pensado). Parte-se da compreensão de que as relações cotidianas das escolas não se autorreferem, ou seja, não são autônomas, mas interdependentes das relações maiores em que se inserem na sociedade, entendendo que a compreensão da totalidade social depende também da compreensão das particularidades concretas.

Para a elaboração deste trabalho foram utilizadas bibliografias que possibilitam compreender a dinâmica social e as ideologias presentes na educação como forma de adaptação dos indivíduos à sociedade capitalista. Entre alguns autores podemos destacar Acácia Zeneida Kuenzer, Dermeval Saviani e Newton Duarte. Também foi utilizado como fonte o PPP/2009 do Colégio Sesi-PR, a proposta pedagógica elaborada por Márcia Rigon, ${ }^{1}$ enfatizando as

Graduada em Letras Português e Literatura de Língua portuguesa/ oficinas de aprendizagem, bem como as relações deste PPP com os pilares da educação, de Jacques Dellors, e com a transdisciplinaridade, para a qual a obra de Nicolescu (1999) é significativa.

O trabalho está dividido em duas seções. A primeira seção está concentrada na explicação do Projeto Político-Pedagógico do Colégio Sesi-PR, sendo subdividido em Proposta Nacional, na qual são analisados os objetivos utilizados em toda a rede Sesi. A Proposta da Confederação Nacional da Indústria, que descreve o discurso burguês utilizado como explicação do trabalho do Colégio Sesi. Ao fim desta primeira seção apresentamos a metodologia adotada pelo Colégio Sesi-PR, baseada nas Oficinas de Aprendizagem, nas quais o aluno deve aprender fazendo, sendo este um aspecto que difere o Colégio Sesi-PR dos demais colégios da rede Sesi. Na segunda seção estão expressas as categorias advindas da leitura do Projeto Político-Pedagógico do Colégio Sesi-PR, quais sejam: Idealismo; Individualização; Transdisciplinaridade; Ecletismo; Aprender a Aprender; Secundarização do Professor, do Conhecimento e da Escola.

Espera-se contribuir no âmbito da Pedagogia para leituras críticas sobre os PPPs e seus fundamentos, algo essencial para uma atuação crítica e consciente do pedagogo nas escolas e em outras instituições. Ressalta-se, por fim, que este trabalho é também resultado de outros trabalhos que vêm sendo desenvolvidos ao longo do percurso da graduação, e, portanto, é uma síntese superior dos esforços parciais até aqui elaborados (MELO; CAMARGO, 2008; MELO; MELO; CAMARGO, 2010).

\section{Projeto político-pedagógico Colégio SESI: a proposta nacional}

O Serviço Social da Indústria (Sesi), que está presente em todo o país, foi criado em 1946, após a Segunda Guerra Mundial, a fim de garantir qualidade de vida aos trabalhadores da indústria e seus familiares, bem como estabelecer um elo pacificador entre a classe dominante (empresários industriais)

Francês e Literatura de língua francesa pela UFRGS, com especialização na mesma universidade em Linguística e Filologia, com ênfase em Dialetologia, especialização em Língua Inglesa pela University of London, criadora das Oficinas de Aprendizagem, metodologia adotada pelo sistema Fiep para a criação dos Colégios Sesi e consultora do Colégio Sesi desde 2005 . 
e a classe dominada (trabalhadores industriais). Inicialmente, seu papel consiste em fornecer produtos, com baixo custo, essenciais à subsistência do trabalhador: utensílios domésticos, alimentos, atividades de esporte, saúde, lazer e educação.

O que embasa as ações do $\mathrm{Sesi}^{2}$ é a crença de que o desenvolvimento competitivo da indústria brasileira depende da qualidade do ensino ofertado em nosso país e, nesse sentido, ele trabalha com o desenvolvimento de competências e habilidades, que compreendem da educação básica à formação continuada. Para o alcance desses anseios, o Sesi desenvolve os seguintes projetos: inclusão digital para todos, programa enriquecimento do capital cultural, formação do educador, consultoria para educação de qualidade, prêmio Sesi qualidade da educação, programa de educação continuada do trabalhador da indústria, escola de tempo integral, ciências na escola, elevação da escolaridade na indústria e Sesi indústria do conhecimento. A rede Sesi trabalha em parceria com o Serviço Nacional de Aprendizagem Industrial (Senai); enquanto ao primeiro compete a educação básica, ao segundo cabe o papel de formação profissional, ofertando cursos de aprendizado industrial para os alunos, geralmente os que estão cursando o ensino médio, em contraturno, ambos articulando-se para bem atender a demanda industrial, buscando qualificar mão de obra.

Na sociedade atual, é valorizado o trabalhador polivalente, que possui domínio em diversas áreas, sendo adaptável a qualquer exigência do mercado, que possui espírito empreendedor e que esteja em sintonia com as necessidades da indústria, buscando qualificação contínua para acompanhar as mudanças, que ocorrem de forma acelerada. Desta forma, o Sesi procura trabalhar com metodologia diversificada, visando, segundo sua perspectiva, ao amplo desenvolvimento do educando, adaptando-o às demandas da indústria. Baseia-se numa proposta construtivista ${ }^{3}$ calcada nos "novos paradigmas da educação", conforme quer fazer acreditar a autora da proposta do PPP do Colégio Sesi-PR. Na verdade, o documento apresenta caráter neotecnicista ${ }^{4}$

\footnotetext{
${ }^{2}$ O Sesi também volta suas ações para o lazer e a promoção da saúde e qualidade de vida dos trabalhadores, mas essas ações não serão analisadas neste trabalho.

3 Para o estudo da concepção construtivista, consultar Becker (1993). Para a crítica a esta corrente pedagógica, ver Duarte (2000).

4 "O novo patamar tecnológico e as novas organizações criadas para o
}

e unidimensional, pois ressalta a necessidade de formação para o mercado de trabalho por intermédio do Senai. Coloca-se em dúvida, portanto, o "amplo" desenvolvimento do educando presente no discurso empresarial.

O Sesi conta com o apoio do Estado para a realização desses projetos. Alguns dos objetivos e interesses do governo são: redução dos índices de analfabetismo no Brasil, elevação do número de matrículas de alunos na educação básica, educação continuada e na educação profissional. Percebemos claramente uma das características essenciais do Estado Mínimo, em que o governo estabelece parcerias com membros da iniciativa privada, nesse caso com empresários industriais, para o alcance de números que são convertidos em verbas para o país, números que muitas vezes não representam a real situação e que valorizam a quantidade, por vezes deixando de lado a qualidade da educação.

\section{Proposta da Confederação Nacional da In- dústria (CNI) - Educação Para a Nova Indústria $-2007$}

Este documento foi lançado em 2007, devendo ser executado pelo Sesi e Senai, garantindo a destinação de $30 \%$ mais verbas para a educação profissional das referidas entidades. A proposta basicamente afirma que um profissional bem qualificado é aquele em que suas habilidades e competências foram bem desenvolvidas ao longo de seu processo educativo. Assim, procura-se dar ênfase a um projeto diferenciado para cada região, qualificando o trabalhador de acordo com a necessidade regional, fortalecendo, dessa forma, a indústria brasileira, que estará mais forte para competir com o mercado mundial. A educação é vista como fator econômico, indo ao encontro da proposta do Colégio Sesi no trabalho com o "novo paradigma educacional", em que o importante é focar as competências e habilidades do educando, formando um trabalhador mais flexível para atender às demandas do mercado, como podemos observar na seguinte citação:

processo de trabalho no interior da produção capitalista, determinam novas exigências de formação para o trabalhador [...] Desse modo, assiste-se ao surgimento do neotecnicismo, desgarrando a escola de seus determinantes sociais, delineando-se um novo caminho, qual seja: treinar e controlar o desempenho do professor em novas roupagens, cujo foco central parece ser a avaliação." (FREITAS, 1992, p.94). 
A educação é uma das vertentes fundamentais para o crescimento da economia, seja pelo efeito direto sobre a melhoria da produtividade do trabalho - formação de trabalhadores mais eficientes, capital humano - seja pelo aumento da capacidade do país de absorção e geração de novas tecnologias (CNI, 2007, p.9).

Empreendedorismo e criatividade também fazem parte da proposta deste documento, característica bem peculiar do discurso neoliberal - uma pessoa criativa e bem qualificada pode ser um empreendedor com o seu próprio negócio, ou ser “criativo" para lidar com o desemprego. Fica evidenciado na proposta que os trabalhadores da indústria brasileira apresentam baixo nível de escolaridade, sendo isso uma barreira para o crescimento do setor industrial. Tal questão, de cunho histórico, torna-se, assim, um meio de culpabilizar a classe trabalhadora pelo nosso subdesenvolvimento. ${ }^{5}$ Assim, as medidas adotadas seriam estratégias para a elevação do nível educacional desses trabalhadores, oportunizando o acesso à educação básica, não se preocupando em "dar" mais do que isso, afinal o empregado não necessita de uma formação em nível superior, precisa somente do ensino básico e de formação profissional continuada.

Nitidamente separados trabalho intelectual e a atividade prática no trabalho, não havia razão para a integração entre educação geral e educação profissional; estava, pois justificada a diferenciação da oferta, a partir da dualidade estrutural no modo de produção capitalista (KUENZER, 2007, p.5).

Ou seja, há necessidade de profissionais que pensem e outros que executem. Temos, assim, a educação dualista, a fim de atender esse anseio: a educação geral procura preparar para a vida, ou para o ingresso no ensino superior, e o ensino profissional visa à formação de mão de obra para o mercado de trabalho. O ensino profissional para muitos representa uma das únicas formas de continuidade na educação, ou de inserção no mercado de trabalho; no entanto, este vem para aprofundar ainda mais a divisão social, por representar a fragmentação entre teoria e prática que, segundo Kuenzer (2007), deriva

\footnotetext{
${ }^{5}$ A ênfase na escolarização dos trabalhadores não pode ser deslocada da crise e competição intercapitalista em nível global, que faz as burguesias locais buscarem, a todo custo, diferenciais produtivos, como é a educação, que impacta positivamente na produtividade da indústria.
}

da necessidade de valorização do capital. Assim, no Colégio Sesi, no período que compreende a educação básica, seriam desenvolvidas as competências e habilidades, e a formação profissional ficaria a cargo dos cursos ofertados pelo Senai.

A tendência internacional é, inicialmente, priorizar os cursos de formação generalista, para, em seguida e no âmbito da empresa, fazer-se o aprofundamento da especialização, de acordo com as exigências dos novos padrões tecnológicos (CNI, 2007, p.16).

São ressaltados dois objetivos, considerados primordiais, na educação básica e continuada ofertada pelo Sesi: o primeiro é o ensino em tempo integral, com novas formas e instrumentos didáticos, bem como a formação do educador; e o segundo a ampliação de vagas para o ensino básico, dando-se prioridade para os filhos dos trabalhadores da indústria. Desta forma, procura-se educar desde cedo o novo trabalhador industrial segundo os parâmetros contemporâneos da acumulação capitalista.

$\mathrm{Na}$ educação profissional desenvolvida pelo Senai prega-se o "emancipar o indivíduo pelo trabalho" (CNI, 2007, p.28); no entanto, essa emancipação proposta refere-se ao ambiente de trabalho, ou seja, ele é autônomo apenas para exercer sua função de acordo com as capacidades exigidas, mas isso não the confere o poder de tomar decisões por si só, pois está subordinado internamente a uma hierarquia e externamente pressionado pelo desemprego. $\mathrm{Na}$ realidade deseja-se um trabalhador especialista, segundo a concepção de Alves (2001), apto para bem executar determinada máquina, ou máquinas, mas que também tenha iniciativa e esteja preparado para enfrentar os desafios que poderão ser encontrados ao longo do caminho.

Como forma de sustentação e defesa de sua proposta, a Confederação Nacional da Indústria faz um levantamento da defasagem educacional no Brasil, tendo o cenário da educação brasileira como dramático e precário, fato este de que não podemos discordar. No entanto, é importante pensar que é necessária não somente formação de cunho tecnicista em nosso país. A CNI apresenta suas instituições Sesi e Senai como um passo para a melhoria da qualidade da Educação Profissional, atendendo aos anseios das demandas industriais: "Visa resgatar valores básicos da cidadania ao oferecer uma 
oportunidade de qualidade para o desenvolvimento pessoal e social dos filhos dos trabalhadores da indústria" (CNI, 2007, p.46). Como em toda proposta, a visão é fornecer apenas o básico aos filhos dos trabalhadores, o mínimo para que consigam bem exercer sua função dentro da indústria.

\section{Metodologia do Colégio Sesi-PR}

O Colégio Sesi-Educação Infantil e Ensino Médio de Guarapuava faz parte da rede Sesi, estando de acordo com a Lei de Diretrizes e Bases da Educação 9.394/96, em que se apresenta como instituição de ensino privado, tendo como mantenedora a Confederação Nacional da Indústria. São seguidos os mesmos preceitos de toda a rede, no entanto trabalha-se de forma independente, aplicando como proposta metodológica inovadora as Oficinas de Aprendizagem, elaboradas por Márcia C. Rigon. De acordo, com a Proposta Pedagógica 2009 do Colégio Sesi:

[...] denominam-se Oficinas de Aprendizagem: oficina no sentido de fazer, manipular, construir, e de aprendizagem, porque envolve o conhecimento. Os alunos são levados a construir conhecimento, num processo dialógico coletivo. (COLÉGIO SESI-PR, 2009, p.20-1).

Como podemos evidenciar, tal proposta apresenta fortes traços do neotecnicismo, enfatizando o aprender a fazer, e, ao mesmo tempo, é construtivista, na medida em que o aluno possui a liberdade de escolher o que quer aprender.

No Programa de Capacitação dos Profissionais do Colégio Sesi-PR, 2007, Rigon compara a escola com a empresa, com metas e objetivos a serem cumpridos, afirmando que esta ficou no passado em relação às mudanças ocorridas na sociedade, com o mesmo conceito de: "poder centralizador do professor, dominando pelo 'conhecimento'(?); uma relação de oprimido e opressor" (RIGON, 2007, p.4). Para a autora, as Oficinas de Aprendizagem vêm para fazer a mudança, e o Colégio Sesi-PR, como adepto desse novo método, vem para quebrar os paradigmas tradicionais, e assim construir novas formas de ensino e aprendizagem.

Para a implantação das Oficinas, Rigon afirma ser necessário, de antemão, mudanças, as quais são: físicas, de abordagem e de ambiente escolar. Tirando o foco do professor - este não pode mais ser o detentor do conhecimento -, o enfoque será dado ao processo de ensino-aprendizado, o qual se dará por meio da formulação, análise e solução de problemas, visando à formação de um aluno líder, criativo e empreendedor, que corra atrás do sucesso. Notamos nesse momento a secundarização da função do professor e características do construtivismo, sendo perceptível o ecletismo presente, em que ora o PPP apresenta-se tecnicista, ora construtivista, e em alguns momentos ainda afirmando ser histórico crítico.

Na visão de Rigon, o aprendizado por oficinas é o aprender fazendo, o qual faz parte do relatório Educação: um tesouro a descobrir - Relatório para a Unesco da Comissão Internacional sobre Educação para o século XXI, proposto por Jacques Delors. O aprender a fazer "está mais estreitamente ligado à questão da formação profissional: como ensinar o aluno a pôr em prática os seus conhecimentos e, como adaptar a educação ao trabalho futuro" (DELORS, 1996), em que são valorizadas as técnicas e formas de ensino e aprendizado, sendo o professor uma "ponte" entre o conhecimento e o aluno. $\mathrm{O}$ professor, para atuar nas Oficinas de Aprendizagem, deve ser líder, facilitador, gerente da sala de aula e ter domínio de estratégias. "Ele orienta os passos, a sequência a ser seguida; pode mostrar possibilidades de caminho, mas ele não faz a aula, ele não dá aula. Ele deixa de ser informante, para ser facilitador" (RIGON, 2007, p.11 - grifos da autora), características estas básicas de um administrador de empresas, que foca resultados para aumento de produção. "Ao aluno, cabe o ofício - que é o dever, o encargo, a incumbência de fazer - o aprender. O ofício é um papel e um serviço" (RIGON, 2007, p.11). A função do aluno é, portanto, a mesma do operário na fábrica. Sendo assim, a escola assume seu papel de empresa, concepção presente na perspectiva neotecnicista. Formar pessoas que:

[...] farão a diferença no mercado de trabalho, por sua formação de empreendedores e líderes, de pessoas autoconfiantes, que aprenderam estando envolvidos nos processos, aprendendo o que era significativo para as suas vidas, transferindo todo este conhecimento e esta abordagem para a vida profissional. (RIGON, 2007, p.9). 
Na citação acima fica clara a intenção da proposta do Colégio Sesi-PR, ou seja, a formação do trabalhador adaptado a essa nova sociedade e às exigências do mercado. Conforme Rigon (2007, p.16):

Os velhos pressupostos geram indagações a respeito de como alcançar normas, obediência e resposta corretas. Os novos levam a questões sobre a motivação para o aprendizado de toda a vida, o reforço da autodisciplina, o despertar da curiosidade e o estímulo ao risco criativo em pessoas de todas as idades.

Ficam assim explicitados os antigos e novos paradigmas, definidos pelo Sesi: o primeiro valoriza a obediência; já o segundo vai ao encontro da proposta das oficinas de aprendizagem, enfatizando autonomia e criatividade, características que irão definir o perfil do novo trabalhador da indústria.

Analisando ingenuamente essas propostas, podemos acreditar em uma metodologia inovadora, algo cativante para professor e aluno, que vem para "transformar". No entanto, toda a proposta do Colégio Sesi e sua mantenedora, CNI, é encoberta pela ideologia capitalista. Seu objetivo primordial é apenas a formação do trabalhador adaptável ao sistema, atendendo aos anseios da indústria, auxiliando, dessa forma, na reprodução de classe. Um trabalhador alienado não tem consciência da exploração que sofre, e ideologias como estas fazem que ele acredite que é valorizado; toda a motivação e benefícios concedidos a ele visam apenas ao aumento de sua produtividade. O trabalhador, assim como era definido por Frederico Winslow Taylor, é apenas uma peça componente da máquina, e deve estar funcionando perfeitamente, pois caso venha a apresentar algum defeito, poderá representar grandes prejuízos ao capitalista.

Assim, a formação do trabalhador definida pelo Colégio Sesi vem para fazer a manutenção da peça componente da máquina, buscando educar o aluno, futuro trabalhador da indústria, desde a educação infantil, sendo aprimoradas as competências e habilidades no Ensino Médio, do qual ele já sairá adaptado ao mercado de trabalho.

\section{Categorias advindas da leitura do projeto político-pedagógico do Colégio SESI-PR}

nesta seção iremos nos concentrar nas categorias retiradas da leitura do Projeto Pedagógico do Colégio Sesi-PR 2009, que serão discutidas ao longo do texto, sendo confluídas com outros autores.

De acordo com Casagrande, Albuquerque e Taffarel (2005), baseados em Marx (1983), Cheptulin (1982), Kopnin (1978), Minayo (2004) e Kuenzer (1998), a produção de conhecimento científico de qualidade necessita da utilização de categorias, de forma precisa, facilmente compreendidas por parte dos leitores. As categorias da dialética materialista representam o movimento do pensamento, o movimento vivo da realidade, sendo que estas podem ser "categorias metodológicas: [...] práxis, totalidade, contradição e mediação" (CASAGRANDE, ALBUQUERQUE, TAFFAREL, 2005, p.2). Categorias de conteúdo: mediação entre universal e concreto. (CASAGRANDE, ALBUQUERQUE, TAFFAREL, 2005). Também temos as categorias analíticas: retêm as relações fundamentais; e empíricas: construídas com finalidade operacional, visando o trabalho de campo (CASAGRANDE, ALBUQUERQUE, TAFFAREL, 2005).

\section{Idealismo $^{6}$}

Esta categoria está intimamente ligada à transdisciplinaridade, que será destacada posteriormente. Segundo a visão idealista encontrada no PPP do Colégio Sesi, a educação é caracterizada como transformadora do mundo, sem, no entanto, basear-se na realidade presente, como observamos no trecho a seguir:

[...] a educação deverá ajudar a construir um novo referencial do que seja a existência e a vida no planeta Terra, suas culturas, seu meio ambiente a interdependência, os conflitos e as sucessivas mudanças. Requer uma visão ecológica que reconheça a interdependência fundamental de todos os fenômenos e o perfeito entrosamento dos indivíduos e das sociedades nos processos cíclicos da natureza. (COLÉGIO SESI-PR, 2009, p.13).

\footnotetext{
${ }^{6}$ Esta categoria, "idealismo", baseia-se na crítica que Marx fez a Hegel, ou seja, de uma visão de mundo que abstrai as relações reais entre os homens e constrói uma visão das relações sociais isenta de contradições.
} 
Nesse ponto fala-se do "perfeito entrosamento dos indivíduos e das sociedades" (PPP SESI-PR, 2009, p.13), mas cabe aqui uma indagação sobre isso, já que se trata de uma proposta de formação individualista, que ressalta a importância da competitividade dentro do mercado de trabalho, em que a formação educativa procura contribuir para que o trabalhador torne-se competitivo. Não tem sentido, portanto, falar em "novo referencial", quando, na verdade, se reafirmam referenciais clássicos do capitalismo e de sua forma de sociabilidade.

Pela obra A ideologia alemã, de Marx e Engels (2002), podemos compreender qual o real objetivo de propostas como a do Sesi, que vislumbram um mundo melhor, que estão impregnadas de ideologias, de uma falsa preocupação com a sociedade:

Assim, a moral, a religião, a metafísica e qualquer outra ideologia, tal como as formas de consciência que lhes correspondem, perdem toda a aparência de autonomia. Não tem história, não tem desenvolvimento; serão antes os homens que, desenvolvendo sua produção material e suas relações materiais, transformam, com esta realidade que lhes é própria, o seu pensamento e os produtos desse pensamento [...] Não é a consciência que determina a vida, mas sim a vida que determina a consciência. (MARX; ENGELS, 2002, p.9).

Assim acontece também com as palavras presentes no PPP do Colégio Sesi, que são despidas de história e materialidade. Aparentemente o projeto idealiza um mundo diferente, mas, na verdade, por ser projeto educativo do capital, não é mais que uma forma superestrutural de dominação ideológica. Um conceito bastante trabalhado nesse sentido é o de "desenvolvimento sustentável", como no trecho a seguir:

A educação para o Desenvolvimento Sustentável busca promover a adoção de comportamentos e práticas que permitam a todos uma vida complexa sem privação da satisfação das necessidades básicas. (COLÉGIO SESI-PR, 2009 p.13).

Percebe-se, assim, a ideológica "preocupação" com o planeta e com o desenvolvimento sustentável, mas também se fala da satisfação das necessidades básicas, ou seja, estamos inseridos numa sociedade capitalista, e por consequência consumista e destruidora do ambiente, o que é antagônico com a própria vida na Terra. No entanto, a defesa da sustentabilidade, tão comum na atualidade, não leva em conta esse dado da materialidade, ou seja, retira da análise o processo real de expansão do capitalismo, a qual não é, por si mesma, sustentável.

\section{Individualização}

A individualização é enfatizada em toda a Proposta Pedagógica do Colégio Sesi-PR, referindo-se ao fato de que o indivíduo passa a ser o responsável por tudo o que ocorre em seu meio e na sua vida. No que concerne ao mercado de trabalho, a proposta insiste no desenvolvimento de habilidades e competências de cada indivíduo para que este possa melhor desempenhar suas funções dentro da organização, visando ao máximo de eficiência e produtividade e, ao mesmo tempo, torne-se empregável. Há também um apelo ao "autoconhecimento", ou seja, apelo para que os alunos, em meio ao mundo cada vez mais complexo, possam se conhecer e descobrir os caminhos para os quais devem dirigir seus esforços. O trecho a seguir é bastante contundente com relação a isso.

A educação deve ajudar o aluno a construir sua identidade pelo autoconhecimento, que significa o conhecimento de sua própria natureza humana para saber quem é, qual seu mais alto potencial, quais seus talentos, as suas qualidades e mesmo os limites e defeitos. Pressupõe acesso aos sentimentos, às emoções e aos afetos para que o indivíduo possa entender e orientar o seu próprio comportamento de forma construtiva em direção ao bem comum. Compreendendo a si, compreenderá melhor os outros, podendo desenvolver ações e atitudes que contribuam e promovam transformações nos sistemas externos, sejam quais forem. Acreditamos que a transformação do mundo se efetua a partir do próprio indivíduo, produto e parte da existência humana. Portanto, o processo educacional deve oportunizar o desenvolvimento da inteligência intrapessoal, bem como interpessoal. (COLÉGIO SESI-PR, 2009, p.13).

Interessante notar que o projeto traz uma concepção de que, a partir do autoconhecimento, o indivíduo pode modificar seu meio, e de que o mundo se resume à somatória dos indivíduos, ou seja, se cada um melhorar, o mundo também melhora. Esse tipo 
de ideologia é adaptado aos tempos neoliberais, de exacerbamento do individualismo, e a solução individualista não deixa de ter sua eficácia quando as pessoas acreditam que nela está o centro de tudo. Conhecer-se para conhecer ao outro; mudar a si para mudar o próximo, parece ser este o lema do Colégio Sesi-PR.

Novamente vemos uma proposta idealista, pois desconsidera que a humanidade sempre se constituiu não como somatória de indivíduos, mas como sociedade, que é a única forma de ser do homem (o homem é um ser social, já diziam Marx e Engels). Logo, desconsiderar o homem como ser social e a sociedade como forma humana por excelência é uma boa maneira de desvincular os problemas sociais, que são evidentes, da estrutura extremamente desigual e destruidora do capitalismo e do capital.

Como poderemos evidenciar na citação a seguir, o Colégio Sesi procura trabalhar de forma individualizada com cada aluno, tentando suprir os déficits de aprendizado e auxiliando-o para compreensão de mundo.

A tarefa educacional que a Rede Sesi de Educação assume é a de ensinar a cada um na medida de suas possibilidades, dar opções e oportunidades de aprender de acordo com suas capacidades e as suas inteligências, fazê-los avançar em suas potencialidades, lembrando que cada ser humano é o seu próprio agente de decisão e responsabilidade para um mundo diferente e melhor. Vemos a educação como um processo de descoberta de potencialidades, a liderança de todos os atores do processo. (COLÉGIO SESI-PR, 2009, p.14).

Acima fica expressa uma "visão platônica" de educação, em que se retira do íntimo de cada um potencialidades, capacidades, habilidades e inteligência, sendo cada um responsável pelo mundo em que está inserido, visão individualista e idealizada de educação.

No mercado de trabalho atual, a competitividade é aguçada entre os trabalhadores, visando ao aumento produtivo. Dessa forma, os indivíduos acabam tendo uns aos outros como inimigos, sendo cada um responsável por sua função, gerando o individualismo dentro das organizações, o que podemos perceber na seguinte citação:

A nova organização exige um novo trabalhador, que deverá possuir novas características. O indi- vidualismo é uma delas. Constituindo-se como uma das respostas da mudança nas organizações, o individualismo marca uma nova forma de relacionamento dentro da empresa. (CASTELHANO, 2005, p.18).

Ou seja, para as empresas o individualismo é necessário, pois gera as competições entre os funcionários. Assim, um quer produzir mais que o outro, gerando mais lucros para o capitalista, e os colegas tornam-se rivais. O indivíduo também acaba sendo responsabilizado por seu sucesso ou fracasso. No individualismo, os trabalhadores perdem a visão coletiva e da totalidade, não se preocupam com as melhorias no ambiente de trabalho, e não se organizam para reivindicar seus direitos. Esses fatos se aliam ao medo do desemprego; assim, a angústia é convertida em maior produção.

\section{Transdisciplinaridade}

O termo transdisciplinaridade muitas vezes é confundido com os termos interdisciplinaridade, multidisciplinaridade e pluridisciplinaridade, porém eles possuem distinção entre si. A transdisciplinaridade pretende ir além das demais, e nessa busca chega a apresentar-se com um caráter idealista e salvacionista tanto para os problemas educacionais como para os problemas sociais. Ela vem para apresentar respostas, assim como podemos perceber na proposta do Colégio Sesi-PR, 2009:

A visão sistêmica ou holística de educação busca a superação da fragmentação do conhecimento, o resgate do ser humano em sua totalidade, considerando o homem com suas inteligências múltiplas, levando a formação de um ser humano não só racional, mas ético e sensível. (COLÉGIO SESI-PR, 2009, p.13).

Ou seja, essa visão sistêmica, assim adotada, refere-se à sistematicidade organizacional aplicada na empresa e incorporada no Colégio Sesi-PR, em que se busca um projeto ideal. A escola é comparada à organização empresarial; ocorrendo a divisão do homem, ele perde sua totalidade e torna-se apenas uma somatória de aspectos, "inteligências" e talentos. O colégio Sesi, por meio de sua proposta:

[...] realizará a interdisciplinaridade, superando as barreiras ideológicas, culturais e históricas entre 
as disciplinas. Os professores trabalhando de maneira a aproveitar os conhecimentos específicos para um mesmo estudo ou aprendizado. A partir daí se terá situação favorável à construção de um plano maior: a transdisciplinaridade. (COLÉGIO SESI-PR, 2009, p.22).

Os termos interdisciplinaridade e pluridisciplinaridade começam a aparecer, a partir do século XIX, com o intuito de estabelecer ligações entre as diversas disciplinas dos currículos escolares: "A pluridisciplinaridade diz respeito ao estudo de um objeto de uma mesma e única disciplina por várias disciplinas ao mesmo tempo" (NICOLESCU, 1999, p.50). No entanto, esta ainda refere-se apenas a uma disciplina. A interdisciplinaridade "diz respeito à transferência de métodos de uma disciplina para outra" (NICOLESCU, 1999, p.50). Mas nenhuma delas dá suporte à compreensão da realidade presente.

Segundo Nicolescu (1999, p.51):

A transdisciplinaridade, como o prefixo 'trans' indica, diz respeito àquilo que está ao mesmo tempo entre as disciplinas, através das diferentes disciplinas e além de qualquer disciplina. Seu objetivo é a compreensão do mundo presente, para qual um dos imperativos é a unidade do conhecimento.

Percebemos a definição acima citada de transdisciplinaridade na seguinte passagem do PPP do Colégio Sesi-PR, 2009:

[...] as oficinas de aprendizagem são constituídas como estruturas flexíveis, em torno de um desafio central, contextualizado num tema, com modo de funcionamento semelhante a uma rede de significados. Essa rede não prioriza disciplinas, mas, sim, a natureza de um problema que na verdade é interdisciplinar e real, sem caráter artificial. (COLÉGIO SESI-PR, 2009, p.19).

Neste ponto fica expresso o conceito de transdisciplinaridade como definida por Nicolescu, em que esta não prioriza uma única disciplina e busca a compreensão do mundo presente. No entanto, a transdisciplinaridade em seu cerne nega o materialismo/histórico/dialético e apropria-se de uma visão idealista de educação, buscando a formação de um ser ideal, colocando o conhecimento como objeto de transformação social. No entanto, esses ideais são encobertos por ideologias de cunho capitalista, com a finalidade de obscurecer a realidade, acreditam na satisfação pessoal através do individualismo e escondem a alienação.

\section{Ecletismo}

Como em diversas propostas, dentre as quais se destacam os Parâmetros Curriculares Nacionais (DUARTE, 2000), encontramos no PPP do Colégio Sesi-PR. Esta escola adota autores variados, de concepções diversas e antagônicas, como, por exemplo, Wallon, Vigotski, Piaget, Paulo Freire e, a partir desse ecletismo, adota uma postura construtivista, criticando as teorias tradicionais. Ao mesmo tempo, trata do "sujeito histórico-cultural" e acaba por se contradizer, pois visa à formação para o trabalho, concepção tecnicista e neoliberal - esta não é ressaltada na proposta, fica implícita. Comenta-se que "Para Paulo Freire, a realidade social está pautada na trama de relações e das correlações que formam a totalidade social" (PROPOSTA PEDAGÓGICA COLÉGIO SESI-PR, 2009, p.17), confrontando isso com a ideia de que "Para Vigotski: o homem é um ser social" (COLÉGIO SESI-PR, 2009, p.17).

Em seu PPP o Sesi afirma que trabalha com o currículo em ação:

[...] no qual a abordagem dos conteúdos das várias áreas do conhecimento dá-se por meio da apropriação dos significados dos conceitos estruturantes que as embasam e que, indubitavelmente, estão interligados. (COLÉGIO SESI-PR, 2009, p.23).

Também estão presentes no PPP as seguintes propostas: Interdisciplinaridade e Transdisciplinaridade, Interseriação, Competências e Habilidades, Contextualização e Preparação para o Mundo do Trabalho, esta última fazendo aproximação clara com uma proposta neotecnicista. Podemos evidenciar na citação a seguir a preocupação para a formação de mão de obra, a fim de atender à demanda industrial.

O Colégio Sesi trabalhará no ensino médio de modo a desenvolver as competências e habilidades gerais e específicas e o trabalho com os conteúdos, [...], os quais devem ser constantemente reavaliados e atualizados face às mudanças e necessidades emergentes (COLÉGIO SESI-PR, 2009, p.26).

A partir dessa citação são descritos os quatro pilares da educação, propostos no relatório 
Jacques Delors (1996), que, por sua vez, entram em contradição com a Pedagogia libertadora de Freire, autor citado no PPP, feita apenas uma apropriação de algo que talvez lhes conviessem no momento. Podemos afirmar, assim como Newton Duarte (2001, p.90), que:

Com um critério tão vago e impreciso, as portas estão abertas para todo o tipo de ecletismo e o único critério para recortar esta ou aquela ideia deste ou daquele autor e depois formar uma grande colcha de retalho é o pragmatismo que, como é sabido, tão bem caracteriza o ideário neoliberal. [...] Defender o "pragmatismo teórico", que é sinônimo de ecletismo pragmático, é aliar-se às forças que lutam pela perpetuação do capitalismo.

Podemos notar que o Sesi-PR, para defender sua proposta pedagógica, apropria-se de forma eclética de ideias e autores, chegando a apresentar duas ou mais teorias antagônicas, desde que estejam pragmaticamente vinculadas com seu objetivo final, que é a preparação para o mercado de trabalho.

\section{Aprender a aprender}

No Sesi valoriza-se exatamente a proposta de Jacques Delors (1996) Educação: um tesouro a descobrir - Relatório para a Unesco da Comissão Internacional sobre Educação para o século XXI, quais sejam, o "aprender a ser", o "aprender a conhecer", o "aprender a viver juntos" e o "aprender a fazer", o qual é enfatizado por meio das oficinas de aprendizagem:

A metodologia que melhor responde a esses anseios é a de pesquisa e a de resolução de problemas, onde os alunos são formados para elaborar estratégias, estudo de alternativas e tomadas de decisão, frente aos problemas, mobilizando suas competências e habilidades. Para isso precisam aprender a investigar, dominar diferentes formas de acesso à informação, desenvolver capacidade crítica de avaliar, reunir e organizar as informações mais relevantes. Requer desenvolvimento de competências e habilidades para manejar e produzir conhecimento, que levem ao questionamento, manifestações de curiosidade e criatividade e ao seu posicionamento como sujeito diante da vida. (COLÉGIO SESI-PR, 2009, p.16). ${ }^{7}$

\footnotetext{
${ }^{7}$ Está claro que o fato de o estudante poder resolver problemas e ter capacidade crítica, assim como competências e habilidades, não é, em si,
}

Nas Oficinas de Aprendizagem podem ser notados explicitamente os quatro pilares da educação, o "aprender a conhecer", que, segundo Delors (1994, p.2), "[...] supõe, antes de tudo, 'aprender a aprender', exercitando a atenção, a memória e o pensamento".

O aprender a aprender é uma ideia defendida desde a Escola Nova e também pelo construtivismo, que visam o desenvolvimento de competências e habilidades. Esse ideário muitas vezes é distorcido, comparando-se com o conceito de zona de desenvolvimento proximal, de Vigotski. Segundo Newton Duarte (2001, p.24):

As pedagogias centradas no lema 'aprender a aprender' são antes de mais nada pedagogias que retiram da escola a tarefa de transmissão do conhecimento objetivo, a tarefa de possibilitar aos educando o acesso à verdade.

Essa afirmação de Duarte sustenta a nossa crítica à proposta do Colégio Sesi-PR, a qual busca desarticular o conhecimento científico, disseminando ideologias aos alunos, secundarizando o conhecimento científico e o professor. Tanto é assim que a prática pedagógica do Colégio Sesi-PR não permite a ação de explanação do professor, ou seja, a aula expositiva é minimizada por ser considerada uma prática "tradicional" e não condizente com o processo de aprendizagem autônoma defendido pela proposta.

[...] o lema "aprender a aprender" passa a ser revigorado nos meios educacionais, pois preconiza que à escola não caberia a tarefa de transmitir o saber objetivo, mas sim a de preparar os indivíduos para aprenderem aquilo que deles for exigido pelo processo de adaptação às alienadas e alienantes relações sociais que presidem o capitalismo contemporâneo. A essência do lema "aprender a aprender" é exatamente o esvaziamento do trabalho educativo escolar, transformando-o num processo sem conteúdo. (DUARTE, 2001, p.29).

A escola unilateral focada no lema aprender a aprender visa à reprodução capitalista, ao aprimoramento das elites e à formação para o trabalho das classes dominadas, sendo esta uma importante

ruim, ao contrário, é desejável que alcance estas possibilidades. No entanto, quando tais conceitos estão no interior das propostas empresariais, ficam reduzidos a um pragmatismo que significa nada mais que a adequação dos futuros trabalhadores às demandas da empresa. 
forma de adequação ideológica do trabalhador. Nesse sentido, é de suma importância a luta pela escola unitária, a qual representa a superação das propostas educacionais burguesas, se assim as podemos chamar, pois tais propostas fundamentam-se em saberes técnicos, de formação para o trabalho, sem preocupação com o desenvolvimento histórico-crítico do indivíduo, tornando-se na verdade uma (de)formação do intelecto e formação da mão de obra para o mercado de trabalho.

\section{Secundarização do professor, do conheci- mento e da escola como disseminadora do conhe- cimento}

Apesar das diversas contradições internas do PPP do Colégio Sesi-PR, sabemos que sua proposta é construtivista, revestida por um viés neotecnicista. O aluno é "autônomo" para construir seu conhecimento, aprende fazendo, por meio das Oficinas de Aprendizagem. Analisemos o posicionamento de Newton Duarte (1998, s/p):

[...] um posicionamento negativo em relação ao ato de ensinar seria o das concepções pedagógicas que, como no caso do Construtivismo, respaldam-se em teorias psicológicas que valorizam as aprendizagens que o indivíduo realiza sozinho, como qualitativamente superiores àquelas onde o indivíduo assimila conhecimento através da transmissão de outras pessoas. Dentro do próprio Construtivismo existem muitas variações quanto a essa questão. Algumas posições mais extremadas tendem a considerar o processo de desenvolvimento psíquico do indivíduo como independente da assimilação dos conhecimentos socialmente existentes.

Como um "exemplo" da proposta tecnicista empresarial, os procedimentos, as técnicas, as formas como se dá o conhecimento são mais importantes que o professor. O conhecimento pode ser construído em diversos ambientes, não necessariamente em sala de aula, ou seja, em relações sociais, com a comunidade, familiares, na rua, secundarizando-se também o conhecimento. Deixando de ser prioridade da escola a elaboração do conhecimento científico, e uma vez que este é adquirido em qualquer relação social, acaba sendo apenas de senso comum. O aluno:
Num processo de auto-organização, é levado a construir sua autonomia o que implica em aprender a aprender, aprender a pensar, com base nas construções que faz como sujeito, nas relações que estabelece com os colegas, com o professor, supostamente mais experiente bem como os demais espaços e pessoas com quem interage cotidianamente. (COLÉGIO SESI-PR, 2009, p.16, grifo nosso).

Percebemos que nessa proposta o professor não é considerado mais experiente e não possui o conhecimento científico mais elaborado que o educando; ocorre nesse momento a secundarização do professor e da escola.

[...] o professor é um sujeito que deve se colocar na situação de eterno aprendiz, de educador-educando. É um sujeito mais pesquisador que transmissor, comprometido com o futuro no presente em sala de aula, ocupado com a atualização constante, com a negociação das propostas de trabalho coletivas na escola. O papel do professor, como educador, é o de mediador e facilitador entre o aluno e o conhecimento, não um mero transmissor de conteúdos. (COLÉGIO SESI-PR, 2009, p.19-21).

Tal proposta vai contra o que Saviani (2008) afirma em seu livro Pedagogia histórico-crítica, que para o alcance de seus objetivos materiais, o homem necessita fazer representações mentais, que incluem "[...] o aspecto de conhecimento das propriedades do mundo real (ciência), de valorização (ética) e de simbolização (arte)" (SAVIANI, 2008, p.12).

Sendo assim, não devem ser desvalorizados os conhecimentos adquiridos no cotidiano do aluno, e sim devem ser aprimorados, elaborados cientificamente com o auxílio do professor e da escola. "A escola tem o papel de possibilitar o acesso das novas gerações ao mundo do saber sistematizado, do saber metódico, científico" (SAVIANI, 2008, p.75). De acordo com a proposta do Colégio Sesi-PR (2009, p.25): “[...] para o currículo em ação proposto, o desenvolvimento de competências são tão importantes quanto os conteúdos em si. Os conteúdos são um meio para desenvolver competências e responder aos desafios".

Essa nova proposta, denominada construtivista, representa a deformação do indivíduo. "É por essa razão que a pedagogia histórico-crítica deve defender, de forma radical, que o papel da escola 
consiste em socializar o saber objetivo historicamente produzido" (DUARTE, 2001, p.29). Somente esse saber historicamente produzido oportunizará aos alunos a compreensão da realidade, dando alicerce para a organização de forças a fim de superar o capitalismo.

$\mathrm{O}$ ato de educar deve superar qualquer tipo ou forma de alienação, ou de adaptação do indivíduo à sociedade capitalista; o conhecimento adquirido na escola deve atender às seguintes especificidades: ser histórico, cultural, produzido coletivamente e ser científico, dando ao educando meios para o desenvolvimento do raciocínio crítico e reflexivo, consciente do poder da mobilização social para a transformação da sociedade.

\section{Considerações finais}

Neste trabalho nos propusemos a estudar a formação do trabalhador da indústria por meio da educação básica ofertada no Colégio Sesi-PR. Para isso, foi realizada a análise crítica do PPP do referido colégio, buscando compreender como este se articula para atender aos anseios da concepção educacional empresarial, especialmente da CNI. Para que esta análise não ficasse no senso comum ou ocorresse de forma ingênua, foram utilizadas as referências que fundamentam a compreensão da formação realizada pelo Colégio Sesi-PR.

Sabemos que a Educação e a Escola não são a-históricas nem apolíticas. Estas se encontram inseridas em um amplo contexto social, sendo os modos de produção determinantes do seu funcionamento em cada contexto histórico. Assim, uma proposta que se baseia no idealismo e na transdisciplinaridade, como é o caso do projeto aqui analisado, claramente atende aos anseios capitalistas pela formação de trabalhadores adaptados à produção de mais-valia.

O currículo do Colégio Sesi-PR baseia-se no aprender a aprender e no aprender a fazer. Notamos o caráter neotecnicista, em que o professor é apenas intermediário do processo de ensino-aprendizado e o conhecimento científico não é primordial, frente, por exemplo, à formação de valores e atitudes expressos pelo empreendedorismo e empregabilidade, que são básicos no projeto do Colégio Sesi-PR. As Oficinas de Aprendizagem, por outro lado, demons- tram que o mais importante são os meios e técnicas para que ocorra esse aprendizado, e não o conteúdo científico. Dessa forma, conhecimento, professor e escola são secundarizados, não ocorrendo a formação crítica do indivíduo, e sim a sua alienação, para que fique adaptável ao mundo do trabalho.

Temos consciência que este estudo é apenas introdutório; mas ele já nos permite analisar criticamente este e outros PPPs, papel fundamental para uma atuação pedagógica consistente. Este estudo abre também a oportunidade de estudos futuros que possam realizar comparações entre propostas como as do Colégio Sesi-PR com as escolas estaduais.

\section{Referências}

ALVES, Gilberto Luiz. A produção da escola pública contemporânea. Campo Grande: EdUFMT; Campinas: Autores Associados, 2001.

BECKER, F. O que é construtivismo. Idéias. São Paulo: FDE, n.20, p.87-93, 1993.

COLÉGIO SESI-PR. Proposta pedagógica 2009. Guarapuava: Colégio SESI - Ensino Médio, 2009. (mimeo).

CONFEDERAÇÃO NACIONAL DA INDÚSTRIA. Educação para a nova indústria: uma ação para o desenvolvimento sustentável do Brasil. Brasília: CNI, 2007.

CASAGRANDE, N; ALBUQUERQUE, J; TAFFAREL, C. Teoria do conhecimento: o que são as categorias. Universidade Federal da Bahia. Curso de Metodologia e Pesquisa em Educação Física\& Esporte e Lazer. Turma I -2005 (mimeo).

CASTELHANO, L. M. O medo do desemprego e a(s) nova(s) organizações de trabalho. Psicologia e Sociedade, Porto Alegre, v. 17, n.1, jan/abr. 2005. Disponível em: $<$ http://www.scielo.br/pdf/psoc/v17n1/a03v17n1.pdf $>$. Acesso em: 1 jun. 2011.

DELORS, J. Educação um tesouro a descobrir: relatório para a UNESCO da Comissão Internacional sobre Educação para o século XXI. UNESCO. 1996.

DUARTE, N. Vigotski e o "aprender a aprender": crítica às aproximações neoliberais se pós-modernas da teoria Vigotskiana. 2. ed. Campinas: Autores Associados, 2001.

Concepções afirmativas e negativas sobre o ato de ensinar. Cadernos CEDES. Campinas, v. 19, n.44, abril 1998. Disponível em: <http://www.scielo.br/scielo. php?pid=S0101-32621998000100008\&script $=$ sci arttext>. Acesso em: 1 jun. 2011.

KUENZER, A. Da dualidade assumida à dualidade negada: o discurso da flexibilização justifica a inclusão excludente. 
Educação \& Sociedade, Campinas, v. 28, n. 100 - Especial, p.1153-1178, out. 2007.

MARX, K.; ENGELS, F. A ideologia alemã. São Paulo: Hucitec, 2002.

MELO, A; CAMARGO, A. Oficinas de aprendizagem e adaptação da educação básica ao mundo do trabalho. Guarapuava: UNICENTRO, 2008.

MELO, A; CAMARGO, A. Delineamentos do projeto político pedagógico Colégio SESI-PR: uma breve análise para reflexão. UNICENTRO, 2010

NICOLESCU, B. Manifesto da transdisciplinaridade. São Paulo: Triom, 1999.

RIGON, S. Programa de capacitação. Colégio SESI-PR. Mimeo, 2007.

SAVIANI, D. Pedagogia histórico-crítica: primeiras aproximações. 10.ed. Campinas: Autores Associados, 2008.

Recebido em: 10/02/2012.

Aprovado para publicação em: 27/04/2012 